\title{
Factors Affecting Critical Features of Fundamen- tal Movement Skills in Young Children
}

\author{
Miha Marinsek ${ }^{1}$, Iva Blazevic ${ }^{2}$, Silvester Liposek ${ }^{3}$ \\ Affiliations: 'University of Maribor, Faculty of Education, Maribor, Slovenia, ${ }^{2}$ University of Pula, Faculty of Educational \\ Sciences, Croatia, ${ }^{3}$ University of Maribor, Faculty of Mechanical Engineering, Maribor, Slovenia
}

Correspondence: M. Marinšek, University of Maribor, Faculty of Education, Koroška cesta 160, 2000 Maribor, Slovenia, e mail:miha.marinsek@um.si

ABSTRACT Despite significant advances in the knowledge and understanding of associations between the phenomenon of excess body weight (hereafter "overweightness") and fundamental movement skill (FMS) proficiency, the question of how overweightness affects critical features of movement remains unanswered. This study examined the differences in the proficiency of FMS between boys and girls with different weight status on the level of critical features. Three hundred and twenty-two boys and girls aged 5 to 10 years were assessed in eight FMS (run, vertical jump, long jump, ball catch, ball kick, ball pass, ball bounce, and forehand strike) and were assigned to non-overweight and overweight groups according to their waist-to-height ratio, with a cut-off point of 0.5 . FMS score differences $(\mathrm{p}<0.05)$ between boys and girls that can be frequently observed in the non-overweight group of children were not determined in the overweight group of children $(\mathrm{p} \geq 0.131)$. Overweight boys performed worse in a higher number of skills' critical features than overweight girls did when compared to non-overweight groups. With weight gain, boys might experience a more significant decline in FMS proficiency than girls do because of the higher scores when non-overweight. The critical features of FMS indicate that overweightness might affect postural control and coordination, which this paper discusses.

KEY WORDS body composition, overweight, waist circumference, quality of movement

$@$ MJSSMontenegro

CRITICAL FEATURES OF FUNDAMENTAL MOVEMENT SKILLS

http://mjssm.me/?sekcija=article\&artid=179

\section{Introduction}

Fundamental movement skills (FMS) are part of the lifespan motor development that emerge in the form of immature movement patterns in early childhood, progress through a transitional phase and become efficient, mature patterns in late childhood (Gabbard, 2012; Haywood \& Getchell, 2009; Roberton \& Halverson, 1984). These movement skills are supposed to be the foundation for learning more complex and sport-specific skills in later periods of motor development (Seefeldt, 1980). FMS continue to change during adolescence while sport-specific movement skills are being learned simultaneously. They are usually divided into locomotor skills (running, jumping, hopping, etc.), non-locomotor/stability skills (one-leg stand, pirouettes, etc.), and manipulative/object control skills (catching, bouncing, kicking, etc.).

Every FMS has a specific movement pattern, which is a time-sequenced series of organized movements that define the skill itself (Roberton \& Halverson, 1984). In scholarly literature, two approaches are commonly used to study FMS at the level of its pattern. Roberton (1977) originally developed the first approach based on stage theory, which predicts that human movement develops in an immutable stage sequence. She proposed a model in which movement was broken down into component parts. Components represented parts of movement (overarm throw in her study) that all individuals theoretically exhibit when repeatedly performing a movement task throughout their lifespan (Roberton, 1977). The approach in which stages are proposed for the components of movement rather than for the total movement (traditional stage approach) enables a more flexible and dynamic investigation of development stages. The second approach to study FMS at the level of its pattern is the use of observable behavioural components that together constitute a proficient performance of movement; the approach Okely, Booth, and Chey (2004) describe as "expert" performer. In contrast to the former approach that allows studying changes 
of movement form (pattern) sequentially over time, the latter approach enables distinguishing movers of different proficiency among each other. To draw a distinction between both approaches, the term "critical features" will be used for the parts of the movement when referring to the second approach rather than "components", as originally described by Roberton (1977) and used in the first approach.

A number of studies examined associations between FMS proficiency, sex, and weight status in preschool and primary school children. Boys tend to be more proficient in object control skills in comparison to girls (Barnett, van Beurden, Morgan, Brooks, \& Beard, 2010; Hardy, King, Farrell, Macniven, \& Howlett, 2010; Spessato, Gabbard, Valentini, \& Rudisill, 2012; O’Brien, Belton, \& Issartel, 2016). However, findings regarding locomotor skill proficiency are not consistent. A study conducted by Robinson (2011) found that boys are better than girls in locomotor skills, and in other studies that girls are better than boys (Cliff, Okely, Smith, \& McKeen, 2009; Hardy et al., 2010). There are a couple of studies that showed no difference between sex in locomotor skills (Goodway, Robinson, \& Crowe, 2010; Spessato et al., 2012). Conversely, there is a high consensus in weight status affecting FMS proficiency. An inverse association between FMS competency and weight status was found (Okely et al., 2004). Overweight or obese children tend to be less competent in FMS (Logan, Scrabis-Fletcher, Modlesky, \& Getchell, 2011).

In scholarly literature, many direct (e.g., skinfold, bioimpedance) and indirect (e.g., BMI) measures of body composition are used. One of the indirect measures to effectively monitor body composition during growth is the waist circumference to body height index (Taylor, Williams, Grant, Taylor, \& Goulding, 2011). It has been described as a simple, accurate, and non-age-dependent measure of overweightness and obesity for the general childhood population (Yan et al., 2007). In comparison to the body mass index, it has several advantages. It considers abdominal adiposity, correlates less with age, and is more accurate in identifying overweightness and obesity (Savva et al., 2000; Yan et al., 2007). The waist-to-height ratio (WHtR) is a better marker of metabolic risk during childhood than waist circumference, and it has been suggested that a ratio higher than 0.5 in schoolchildren is related to an increased health risk (McCarthy \& Ashwell, 2006; Browning, Hsieh, \& Ashwell, 2010).

Despite the fact that the main purpose of the study by Okely et al. (2004) was to describe the association between FMS proficiency and two measures of body composition, it revealed a rather inconsistent trend between FMS proficiency, sex, and measures of body composition (BMI and waist circumference) that requires further investigation. The results indicated that non-overweight boys and girls were more likely to be proficient in locomotor skills than overweight boys and girls were. The data confirmed no differences in object control skills between overweight and non-overweight boys and girls. However, these results did not reveal in which critical features of locomotor and object control skills non-overweight boys and girls differ from overweight boys and girls. Because individual features of movement can indicate particular problems in a movement pattern, it would be interesting to see in which critical features the biggest difference occurs when children are overweight; this would thus enable better planning of needed interventions. Furthermore, it would be interesting to determine whether these differences are more frequent in a specific sex.

The purpose of this study was to explore differences in critical features of FMS between overweight and non-overweight children across sex. According to the previously reported data on FMS proficiency scores between overweight and non-overweight boys and girls (Okely et al., 2004), differences in critical features of locomotor skills should be observed; however, no differences in critical features of object control skills should be observed.

\section{Methods}

Participants

Six hundred and five children were invited to participate in the study. Of these, 322 children (a 53\% response rate) aged from five to 10 years (girls $\mathrm{M}=6.4, \mathrm{SD}=2.2$ years; boys $\mathrm{M}=6.3, \mathrm{SD}=2.0$ years), who were enrolled in either a public kindergarten or public elementary school were included in the study. A total of 146 girls (45\%) and 176 boys (55\%) were included in the sample, which was entirely Caucasian. Children whose parents or guardians agreed with the informed consent to participate were recruited. All procedures performed in this study were conducted according to the Declaration of Helsinki principle and were approved by the local ethics committee. The kindergarten or school principals approved each of the participating institutions.

\section{Procedures and measures}

Eight FMS were video-recorded and then assessed with a checklist for each skill. Three locomotor (LOC) skills (run, vertical jump, long jump) and five object control (OC) skills (ball catch, ball kick, ball pass, ball bounce, and forehand strike) were included in the research. These skills were selected because they form the basis for many traditional and popular sports played in Europe (e.g., gymnastics, athletics, basketball, handball, tennis). Each skill was broken down into six critical features, as in Okely et al. (2004). A panel of three experts in FMS assessed content validity; all of them taught on sport science/physical education study programmes at different universities. They reviewed and ranked the importance of the skill and identified and reviewed each skills' critical feature (Okely et al., 2004).

The defined critical features served as qualitative descriptors for skill proficiency. Each critical feature was assessed as possessed or not possessed by three assessors. The children had to demonstrate the component on at least two out of the three attempts for the component to be recorded as possessed. For each possessed component, one point was assigned. The mean sum of three assessors represented the final score. Each participant was therefore given a total score from zero to six on the ordinal scale. A score of zero represented that the participant was not proficient 
in the measured skill and six that the participant was completely proficient in the measured skill. An overall motor proficiency score (MP) was obtained by summing the scores for individual LOC and OC, with a maximum score of 48 points.

Instructions included providing a verbal description and demonstration of the skill. With the instructions, we attempted to create a relevant, meaningful and motivating activity for children, and thus enable the participants an opportunity to demonstrate their proficiency in measured skills (Hands, 2002). No motivational comments were offered to participants during the execution. All children were allowed to practice before being assessed on the three test trials. Trained assessors, who had to demonstrate competency in the FMS assessment protocol prior to the study, assessed skill proficiency.

The inter-assessor reliability of the LOC and OC proficiency scores were evaluated by the proportion of agreement adjusted with Cohen's kappa. Interpreting values for kappa were $<0.20$ poor, 0.21-0.40 fair, 0.41-0.60 moderate, 0.61-0.80 good, and >0.80 very good (Altman, 1991). Cohen's kappa was for LOC 0.81-0.86 and OC 0.78-0.83, indicating good to very good inter-assessor reliability.

Height was measured with a stadiometer and waist circumference with a measuring tape to the nearest $0.1 \mathrm{~cm}$ according to the Anthropometry procedures manual (NHANES, 2007). Waist circumference was measured with anthropometric tape at the level of the iliac crest while the subject was at minimal respiration. According to the WHtR, a score lower than 0.5 was assigned to 243 (76\%) children (110 girls and 133 boys) who formed a non-overweight group, and a score higher than 0.5 was assigned to 79 (24\%) children ( 36 girls and 43 boys) who formed an overweight group.

\section{Statistical analysis}

Different statistical approaches were selected in relation to data typology and an a priori hypothesis. The dependent variables were the overall motor proficiency score (MP), locomotor proficiency score (LOC), and object control proficiency score (OC).

Prior to the analyses, the data were screened for normality using skewness and kurtosis statistics. A skewness value greater than 1 , and a standardized kurtosis value that is less than -2 or greater than +2 indicates that the distribution varies significantly from normal (Green, Salkind, \& Akey, 2000). The calculated statistics suggested that the distributions of the variables were within the expected range (skewness: -0.72 to -0.39 ; kurtosis: -0.43 to -0.81 ).

A MANCOVA with 2 between-participants factors [sex (boys, girls), weight status (non-overweight, overweight)], and 1 covariate [age] was employed to find differences between sex and weight status in MP, LOC, and OC. Pillai's Trace model was used. Prior to conducting the MANCOVA, a series of Pearson correlations were performed between all of the dependent variables in order to test the MANCOVA assumption that the dependent variables would be correlated with each other in the moderate range (Meyers, Gamst, \& Guarino, 2006). A meaningful pattern of correlations was observed amongst all of the dependent variables (all $r>0.80$ ), suggesting the appropriateness of a MANCOVA. Additionally, Leven's test was associated with a p-value of $0.143,0.153$, and 0.088 for MP, LOC, and $\mathrm{OC}$, respectively. Thus, the covariance matrices between the groups were assumed to be equal for the purposes of the MANCOVA.

For significant main effects, follow-up univariate analyses of covariance (ANCOVA) were computed. A Chi-square test was used to determine differences in the proficiency of FMS components between overweight and non-overweight groups across sex. All statistical analyses were performed using IBM SPSS Statistics version 21.0, and an a priori level used to determine the statistical significance was $\mathrm{p}<0.05$.

\section{Results}

The MANCOVA revealed statistically significant difference in $\operatorname{sex}(\mathrm{F}(2,316)=6.92, \mathrm{p}<0.001, \eta \mathrm{p} 2=.04)$ and $\operatorname{WHtR}\left(\mathrm{F}(2,316)=21.69, \mathrm{p}<0.001, \eta \mathrm{p}^{2}=.12\right)$ but not in interaction between sex and $\operatorname{WHtR}(\mathrm{F}(2,316)=1.59$, $\left.\mathrm{p}=0.21, \eta \mathrm{p}^{2}=.01\right)$. Age was a significant $(\mathrm{p}<0.001)$ covariate.

Follow-up ANCOVA showed statistically significant differences between boys and girls in MP and OC scores controlling for age $\left(\mathrm{F}(1,317)=9.89, \mathrm{p}<0.001, \eta \mathrm{p}^{2}=.03\right.$ and $\mathrm{F}(1,317)=12.95, \mathrm{p}<0.001, \eta \mathrm{p}^{2}=.04$, respectively) but not for $\operatorname{LOC}\left(\mathrm{F}(1,317)=3.47, \mathrm{p}=0.06, \eta \mathrm{p}^{2}=.01\right)$. Boys were found to be more proficient in OC (Boys, $\mathrm{M}=21.74$, $\mathrm{SE}=0.39$; Girls, $\mathrm{M}=19.68, \mathrm{SE}=0.43$ ), but not in LOC (Boys, $\mathrm{M}=13.87, \mathrm{SE}=0.25$; Girls, $\mathrm{M}=13.18, \mathrm{SE}=0.28$ ) in comparison to girls. Overall motor proficiency showed better results for boys $(M=35.60, S E=0.59)$ in comparison to girls $(\mathrm{M}=32.85, \mathrm{SE}=0.65)$ (Table 1$)$.

\begin{tabular}{|c|c|c|c|c|c|c|}
\hline & \multicolumn{2}{|c|}{ All Children ( $\mathrm{N}=322$ ) } & \multicolumn{2}{|c|}{ Non-overweight $(\mathrm{N}=243$ ) } & \multicolumn{2}{|c|}{ Overweight $(\mathrm{N}=79)$} \\
\hline & Boys $(\mathrm{N}=176)$ & Girls $(N=146)$ & Boys $(\mathrm{N}=133)$ & Girls $(N=110)$ & Boys $(\mathrm{N}=43)$ & Girls $(N=36)$ \\
\hline MP & $35.60 \pm .59$ & $32.85 \pm .65$ & $39.35 \pm .96$ & $35.39 \pm 1.08$ & $31.86 \pm .73$ & $30.31 \pm .79$ \\
\hline LOC & $13.87 \pm .25$ & $13.18 \pm .28$ & $15.15 \pm .41$ & $14.17 \pm .46$ & $12.62 \pm .31$ & $12.18 \pm .33$ \\
\hline OC & $21.74 \pm .39$ & $19.68 \pm .43$ & $24.23 \pm .63$ & $21.22 \pm .70$ & $19.25 \pm .48$ & $18.13 \pm .51$ \\
\hline
\end{tabular}

Note. Mean \pm standard error; MP: overall motor proficiency; LOC: locomotor skills; OC: object control skills. 
The ANCOVA for non-overweight versus overweight on MP, LOC, and OC scores controlling for age indicated statistically significant differences $\left(\mathrm{F}(1,317)=43.16, \mathrm{p}<0.001, \eta \mathrm{p}^{2}=.12 ; \mathrm{F}(1,317)=30.76, \mathrm{p}<0.001\right.$, $\eta \mathrm{p}^{2}=.09$; and $\mathrm{F}(1,317)=41.95, \mathrm{p}<0.001, \eta \mathrm{p}^{2}=.12$, respectively). Non-overweight children showed better results in $\mathrm{LOC}$ (non-overweight, $\mathrm{M}=14.65, \mathrm{SE}=0.31$; overweight $\mathrm{M}=12.40, \mathrm{SE}=0.23$ ), $\mathrm{OC}$ (non-overweight, $\mathrm{M}=22.72, \mathrm{SE}=0.49$; overweight $\mathrm{M}=18.69, \mathrm{SE}=0.36$ ), and $\mathrm{MP}$ (non-overweight, $\mathrm{M}=37.37, \mathrm{SE}=0.74$; overweight $\mathrm{M}=31.09, \mathrm{SE}=0.55)$ in comparison to overweight children.

Furthermore, we analysed the differences between boys and girls by weight status. The results showed a major discrepancy between overweight and non-overweight boys in MP (Mdiff $=7.49$ points) and OC (Mdiff $=4.98$ points) scores, but a minor discrepancy in LOC (Mdiff $=2.32$ points) scores. However, results revealed a smaller discrepancy between overweight and non-overweight girls when compared to boys (5.08, 3.09 , and 1.99, respectively). Consequently, the differences observed in non-overweight group between boys and girls in MP, LOC, and OC scores $\left(\mathrm{F}(1,76)=14.77, \mathrm{p}<0.001, \eta \mathrm{p}^{2}=.12 ; \mathrm{F}(1,76)=5.08, \mathrm{p}=0.026\right.$, $\eta \mathrm{p}^{2}=.04 ; \mathrm{F}(1,76)=16.82, \mathrm{p}<0.001, \eta \mathrm{p}^{2}=.13$, respectively) could not be observed in the overweight group $\left(\mathrm{F}(1,240)=1.89, \mathrm{p}=0.170, \eta \mathrm{p}^{2}=.01 ; \mathrm{F}(1,240)=.08, \mathrm{p}=0.368, \eta \mathrm{p}^{2}=0.001 ;\right.$ and $\mathrm{F}(1,240)=2.30, \mathrm{p}=0.131$, $\eta \mathrm{p}^{2}=.01$, respectively).

\begin{tabular}{|c|c|c|c|c|c|c|c|}
\hline & \multirow{2}{*}{ Critical features } & \multicolumn{2}{|c|}{ Proficient boys (\%) } & & \multirow{2}{*}{ Critical features } & \multicolumn{2}{|c|}{ Proficient boys (\%) } \\
\hline & & NO & ow & & & NO & OW \\
\hline BK & $\begin{array}{l}\text { Eyes are focused on the ball } \\
\text { throughout the kick, } \\
X^{2}(1)=12.5, P<0.001\end{array}$ & 100.0 & 82.9 & $\mathrm{BC}$ & $\begin{array}{l}\text { Hands and fingers are } \\
\text { opened, } X^{2}(1)=5.1, P= \\
0.035\end{array}$ & 88.5 & 72.3 \\
\hline $\mathrm{BK}$ & $\begin{array}{l}\text { Kicking leg follows through } \\
\text { towards the target after the } \\
\text { ball contact, } X^{2}(1)=12.2 \\
P<0.001\end{array}$ & 93.8 & 72.1 & BK & $\begin{array}{l}\text { Bent knee during the } \\
\text { backswing of the kicking } \\
\text { leg, } X^{2}(1)=4.8, P=0.032\end{array}$ & 84.6 & 68.1 \\
\hline RUN & $\begin{array}{l}\text { Body is leaning slightly for- } \\
\text { ward, } X^{2}(1)=10.02, P=0.001\end{array}$ & 93.8 & 74.8 & & & & \\
\hline VJ & $\begin{array}{l}\text { Crouch with knees bent and } \\
\text { arms behind body, } \mathrm{X}^{2}(1)= \\
7.34, \mathrm{P}=0.008\end{array}$ & 84.6 & 65.8 & & & & \\
\hline VJ & $\begin{array}{l}\text { Balanced landing with no } \\
\text { more than one step in any } \\
\text { direction, } X^{2}(1)=15.3 \text {, } \\
P<0.001\end{array}$ & 90.8 & 64.0 & & & & \\
\hline $\mathrm{BP}$ & $\begin{array}{l}\text { Step towards the target with } \\
\text { optional leg after the pass, } \\
X^{2}(1)=23.14, P<0.001\end{array}$ & 75.4 & 37.8 & & & & \\
\hline BB & $\begin{array}{l}\text { Eyes focused forward } \\
\text { throughout the bounce, } \\
X^{2}(1)=11.06, P=0.001\end{array}$ & 60.0 & 34.2 & & & & \\
\hline BB & $\begin{array}{l}\text { Contact the ball at about hip } \\
\text { height, } X^{2}(1)=22.90 \\
P<0.001\end{array}$ & 76.9 & 39.6 & & & & \\
\hline BB & $\begin{array}{l}\text { Hips and knees slightly flexed } \\
\text { during the bounce, } \\
X^{2}(1)=10.68, P=0.001\end{array}$ & 73.8 & 48.6 & & & & \\
\hline $\mathrm{LJ}$ & $\begin{array}{l}\text { Controlled landing with bent } \\
\text { knees to absorb force of land- } \\
\text { ing, } X^{2}(1)=7.37, P=0.007\end{array}$ & 73.8 & 53.2 & & & & \\
\hline FS & $\begin{array}{l}\text { Eyes are focused on the ball } \\
\text { throughout the strike, } \\
X^{2}(1)=18.7, P<0.001\end{array}$ & 93.8 & 64.9 & & & & \\
\hline FS & $\begin{array}{l}\text { Stand side-on to the target } \\
\text { with bat held in one hand, } \\
X^{2}(1)=9.78, P=0.002\end{array}$ & 80.0 & 56.8 & & & & \\
\hline FS & $\begin{array}{l}\text { Finish the strike in front of the } \\
\text { body, } X^{2}(1)=8.07, P=0.007\end{array}$ & 72.3 & 50.5 & & & & \\
\hline
\end{tabular}

Note. NO: non-overweight; OW: overweight; BK: ball kick; RUN: run; VJ: vertical jump; BP: ball pass; BB: ball bounce; LJ: long jump; FS: forehand strike; BC: ball catch.

To indicate sex-specific discrepancy, we listed the critical features of movement in which we found differences between the overweight and non-overweight groups of children that could be attributed only to boys and girls, respectively (Table 2). The Chi square test revealed that a statistically significant number of overweight boys performed worse in 13 critical features (nine critical features of OC, four critical features of LOC) than non-overweight boys did (all $\mathrm{p} \leq 0.008$ ). The same test revealed differences in only two critical features (both critical features of $\mathrm{OC}$ ) for girls (both $\mathrm{p} \leq 0.022$ ). 


\section{Discussion}

The main finding of the present study is that the sex differences in FMS scores frequently seen in the non-overweight group of children cannot be seen in overweight children. To examine this, we assessed 322 children's FMS proficiency. LOC, OC, and MP scores, as well as a waist-to-height ratio, were assigned to the individual child. The differences were checked across sex and weight status, and age was used as a covariate.

The results of our study concerning sex and weight status differences of all measured participants are in accordance with previously reported results. Boys in our study were found to be more proficient in MP and OC (Barnett et al., 2010; Hardy et al., 2010; Spessato et al., 2012), but not in LOC (Goodway et al., 2010; Spessato et al., 2012). Additionally, the results of our study are in accordance with recent literature that examined non-overweight children and found that they perform FMS better than their overweight counterparts do (Logan et al., 2011). Non-overweight children in our study showed better results in MP, LOC, and OC than overweight children did. The findings are also consistent with studies that used other measurements of body composition, such as waist circumference and BMI (Okely et al., 2004).

However, when sex differences across weight status were compared, we detected that the differences in MP, LOC, and OC were not evident in the overweight group. Overweight boys did not show better performances in MP and OC, nor in LOC, in comparison to overweight girls. Overweight boys experienced a more significant discrepancy in MP, OC, and LOC scores when compared to non-overweight boys in comparison to girls. Thus, the FMS proficiency of overweight boys became, particularly in OC, more similar to the girls. Additionally, overweight boys performed FMS on average worse than non-overweight girls did.

Furthermore, critical features of individual FMS were analysed to understand the background of why the sex differences in LOC and OC scores that were detected in non-overweight children, could not be detected in overweight children. The results showed the discrepancy between overweight and non-overweight boys in a higher number of critical features than between overweight and non-overweight girls. In contrast to non-overweight boys, overweight boys' bodies were not leaning slightly forward when running, their hips and knees were not slightly flexed during the ball bounce, and they did not stand side-on to the target with racket held in one hand for a forehand strike. This might suggest a lack of postural control in overweight boys. It seems that the internal representation of the movement that aids in detecting movement errors is hindered in overweight boys in a way appropriate posture cannot be achieved. One explanation could be that they are directing their attention to other critical features of the movement (e.g., contact the ball at about hip height). This could also explain why overweight boys were unable to maintain sight on the reference points such as on the ball/racket throughout the kick/strike and forward throughout the ball bounce. Another explanation could be that because of their overweightness boys are searching for other motor solutions that enable the execution of the movement. However, these solutions might not be in line with proficient execution. For example, when running, overweight boys tend to lean their body slightly backward, which is incorrect execution but enables them to lift their knees in the phase of the front swing. If they leant slightly forward, it would have made the lift of the knees more difficult or even impossible most probably because of weak hip flexors and abdominal muscles in relation to their heavy legs. Previous research showed that obese children are functionally disadvantaged compared to children of healthy body mass when required to move their larger body mass against gravity, and even when required to perform fundamental daily living activities (Riddiford-Harland, Steele, \& Baur, 2006). The latter could also be the reason that overweight boys lacked proficiency in critical features that might indicate problems in motor control and coordination such as: kicking leg follows through towards the target after the ball contact, balanced and controlled landing with bent knees, contact the ball at about hip height in ball bounce, finish the forehand strike in front of the body, crouch with knees bent and arms behind body, and step towards the target with optional leg after the pass. In FMS, body segments have to be moved in the corresponding time sequence to achieve proficient execution. It seems that overweightness in boys hinders them in applying muscle force in the appropriate time window, and thus makes the optimal performance of movement for them impossible.

In contrast to many critical features that differ between overweight and non-overweight boys, girls showed proficiency difference only in two critical features: hands and fingers were not opened in ball catch, and the knee was not bent during the backswing of the kicking leg in ball kick. These critical features point out a lack of postural control and coordination, as described in boys but to a lesser extent. This can indicate that girls' motor proficiency does not drop as much with overweightness as boys' motor proficiency does. Considering the girls in our study had lower motor proficiency scores in the non-overweight group, they have less room to drop. Boys that scored higher in the non-overweight group have more room to drop.

There are limitations to our study and care should be taken in the generalization of the results, since the number of participants in the age subgroups was relatively small. Additionally, because the data were gathered from a cross-sectional study, we cannot infer the causal direction. Nevertheless, the results indicate a distinct problem of FMS proficiency at the level of critical features in overweight children and boys in particular. The data acquired in our study limit us from making inferences about the origin of the problem. To explain why there is a more significant discrepancy in FMS proficiency between critical features of overweight and non-overweight boys compared to girls further research is needed. Additionally, only a sample of FMS that have been found to be relevant in common sports was selected in the present study. Therefore, the FMS measures do not provide an overall evaluation of a child's FMS proficiency. 


\section{REFERENCES}

Altman, D. G. (1991). Practical statistics for medical research. London: Chapman and Hall.

Barnett, L. M., van Beurden, E., Morgan, P. J., Brooks, L. O., \& Beard, J. R. (2010). Gender differences in motor skill proficiency from childhood to adolescence: A longitudinal study. Research Quarterly for Exercise and Sport, 81(2), 162-170. doi: 10.1080/02701367.2010.10599663

Browning, L. M., Hsieh, S. D., \& Ashwell, M. (2010). A systematic review of waist-to-height ratio as a screening tool for the prediction of cardiovascular disease and diabetes: 0.5 could be a suitable global boundary value. Nutrition Research Reviews, 23(02), 247-269. doi: 10.1017/S0954422410000144

Cliff, D. P., Okely, A. D., Smith, L., \& McKeen, K. (2009). Relationships between fundamental movement skills and objectively measured physical activity in pre-school children. Pediatric exercise science, 21(4), 436439. doi: $10.1123 /$ pes.21.4.436

Gabbard, C. P. (2012). Lifelong motor development (Sixth edition). College Station, TX: Pearson Benjamin Cummings.

Goodway, J. D., Robinson, L. E., \& Crowe, H. (2010). Gender differences in fundamental motor skill development in disadvantaged preschoolers from two geographical regions. Research Quarterly for Exercise and Sport, 81(1), 17-24. doi: 10.1080/02701367.2010.10599624

Green, S. B., Salkind, N. J., \& Akey, T. M. (2000). Using SPSS for windows: Analyzing and understanding data. Englewood Cliffs, NJ: Prentice Hall.

Hands, B. P. (2002). How can we best measure fundamental movement skills? In: Proceeding of the Australian council for health, physical education and recreation Inc. (ACHPER) 23rd biennial national/international conference: interactive health and physical education. Launceston, Tasmania, Australia.

Hardy, L. L., King, L., Farrell, L., Macniven, R., \& Howlett, S. (2010). Fundamental movement skills among Australian preschool children. Journal of Science and Medicine in Sport, 13(5), 503-508. doi: 10.1016/j. jsams.2009.05.010

Haywood, K., \& Getchell, N. (2009). Life Span Motor Development 5th Edition. Champaign, IL: Human Kinetics.

Logan, S. W., Scrabis-Fletcher, K., Modlesky, C., \& Getchell, N. (2011). The relationship between motor skill proficiency and body mass index in preschool children. Research Quarterly for Exercise and Sport, 82(3), 442-448. doi: 10.1080/02701367.2011.10599776

McCarthy, H. D., \& Ashwell, M. (2006). A study of central fatness using waist-to-height ratios in UK children and adolescents over two decades supports the simple message -'keep your waist circumference to less than half your height'. International Journal of Obesity, 30(6), 988-992. doi: 10.1038/sj.ijo.0803226

Meyers, L.S., Gamst, G., \& Guarino, A. (2006). Applied multivariate research: Design and interpretation. Thousand Oaks, CA: Sage Publishers.

National Health and Nutrition Examination Survey (NHANES). (2007). Anthropometry Procedures Manual. Atlanta, GA: Centers for Disease Control and Prevention.

O'Brien, W., Belton, S., \& Issartel, J. (2016). Fundamental movement skill proficiency amongst adolescent youth. Physical Education and Sport Pedagogy, 21(6), 557-571. doi: 10.1080/17408989.2015.1017451

Okely, A. D., Booth, M. L., \& Chey, T. (2004). Relationships between body composition and fundamental movement skills among children and adolescents. Research Quarterly for Exercise and Sport, 75(3), 238247. doi: 10.1080/02701367.2004.10609157

Riddiford-Harland, D. L., Steele, J. R., Baur, L. A. (2006). Upper and lower limb functionality: are these compromised in obese children?. International Journal of Pediatric Obesity, 1(1), 42-49. doi: $10.1080 / 17477160600586606$

Roberton, M. A. (1977). Stability of stage categorizations across trials: Implications for the "stage theory" of overarm throw development. Journal of Human Movement Studies, 3(1), 49-59.

Roberton, M. A., \& Halverson, L. E. (1984). Developing children-their changing movement: A guide for teachers. Lea and Febiger.

Robinson, L. E. (2011). The relationship between perceived physical competence and fundamental motor skills in preschool children. Child Care Health and Development, 37(4), 589-596. doi: 10.1111/j.13652214.2010.01187.x

Savva, S. C., Tornaritis, M., Savva, M. E., Kourides, Y., Panagi, A., Silikiotou, N., ... Kafatos, A. (2000). Waist circumference and waist-to-height ratio are better predictors of cardiovascular disease risk factors in children than body mass index. International Journal of Obesity, 24(11), 1453-1458. doi: 10.1038/sj.ijo.0801401

Seefeldt, V. (1980). Developmental motor patterns: Implications for elementary school physical education. Psychology of Motor Behavior and Sport, 36(6), 314-323.

Spessato, B. C., Gabbard, C., Valentini, N., \& Rudisill, M. (2012). Gender differences in Brazilian children's fundamental movement skill performance. Early Child Development and Care, 183(7), 916-923. doi: $10.1080 / 03004430.2012 .689761$

Taylor, R. W., Williams, S. M., Grant, A. M., Taylor, B. J., \& Goulding, A. (2011). Predictive ability of waist-toheight in relation to adiposity in children is not improved with age and sex-specific values. Obesity, 19(5), 1062-1068. doi: 10.1038/oby.2010.217

Yan, W., Bingxian, H., Hua, Y., Jianghong, D., Jun, C., Dongliang, G., ... Da, M. (2007). Waist-to-height ratio is an accurate and easier index for evaluating obesity in children and adolescents. Obesity, 15(3), 748-752. doi: $10.1038 /$ oby.2007.601 